\title{
TWO (SULFONE-AMIDOSULPHONYL)-AMIDES DERIVED FROM N-(P-AMIDOBENZOYL)-L-GLUTAMINE; OPTIMIZED SYNTHESIS AND TOXICITY STUDY
}

\section{Corina CHEPTEA*, Andreea Celia BENCHEA ${ }^{* *}$, Marius GAINA ${ }^{* *}$, Dana Ortansa DOROHOI ${ }^{* *}$, Valeriu SUNEL ${ }^{* *}$}

\section{" "Grigore T. Popa" Medicine and Pharmacy University, Iași, Romania, "* "Alexandru Ioan Cuza" University, Faculty of Physics, Iași, Romania, *** "Alexandru Ioan Cuza" University, Faculty of Chemistry, Iași, Romania ddorohoi@uaic.ro}

\begin{abstract}
Two derivatives of glutamine were svnthesized and the most convenient phvsical conditions for obtaining reactions were established in factorial experiments with temperature and time of reactions considered as relevant variables. A quantum-mechanical characterization for the new compounds was performed by using HvperChem 8.0.6 Programs and their physical and chemical properties were theoretically estimated. The toxicity of two new compounds was experimentally determined.
\end{abstract}

Keywords: $\mathrm{N}$-[p-(R)-Benzoyl]-L-Glutamine derivatives, factorial experiment for optimization, QSAR parameters, toxicity test.

\section{Introduction}

The sulphonamides occupy an important place between the substances used in bactericidal therapy [1].

The German pathologist and bacteriologist Gerhard Domagk was the first who establish the sulphonamide antibacterial effects [2]. The toxicity and the selectivity of these chemotherapeutic agents largely depend on the possibility of inhibition of folic acid synthesis, indispensable for the formation of nucleic acids, respectively for cell multiplication [3]. Corresponding to the structural analogy with p-aminobenzoic acid, the sulphonamides react, forming folic acid nonfunctional analogues [4-9].

Based on these data it was assumed that glutamine and its derivatives acylated with p- substituted benzoyl group, participating in the metabolism of animal bodies, reduce the toxicity of medicinal products and, at the same time, may become important folic acid antagonists involved at the cellular level.

These data have justified researchers to synthesize new sulfonamides containing in their structure $\mathrm{N}$-(p-aminobenzoyl $)$-Lglutamine.

\section{Experimental part and molecular} modeling

2.1. Synthesis of new sulfonamides of glutamine

The N-[p-methylsalicyl-

amidosulphonyl)-benzoyl]-L-glutamine (I) was obtained in the following way: 0,004 moles $\mathrm{N}$-(p-aminobenzoyl)-L- glutamine, 0.004 moles 5-chlorosulfonyl-methyl salicylate, $25 \mathrm{~mL}$ anhydrous dioxane and 0,2 $\mathrm{mL}$ pyridine were introduced in a flask equipped with ascending refrigerator and the mixture was refluxed for an hour, in a thermostatic silicone bath, at $116-118^{\circ} \mathrm{C}$, in a reaction time of about 58-62 minutes. A light yellow solid compound was separated from the reaction mixture by cooling and 
heating with anhydrous ethylic ether. The pure compound filtered in vacuum dried and by recrystallization from ethyl acetate, melts at $211-213^{\circ} \mathrm{C}$. The reaction yield was $83 \%$ (1,63g).

The N-[p-methyl-phenoxyacetateamidosulphonyl)-benzoyl]-L-glutamine has been obtained in the temperature range $116-120^{\circ} \mathrm{C}$ and reaction time was of about an hour. The compound was prepared starting from 0,004 moles N-(p-aminobenzoyl)-Lglutamine, $30 \mathrm{~mL}$ anhydrous dioxane, 0,004 moles 2-hydroxy-4-chlorosulfonyl-methyl phenoxyacetate and $0,2 \mathrm{~mL}$ pyridine. The pure compound, purified by recrystallization from ethyl acetate, melts at $216-218^{\circ} \mathrm{C}$. The reaction yield was $65 \%(1,24 \mathrm{~g})$.

All reagents were used as purchased (Sigma-Aldrich, Fluka, Merck, S.C. Chemical Company S.A.). The melting points of the obtained compounds were determined with a Mel-Temp melting point module, provided with digital thermometer.

\subsection{HyperChem calculations}

HyperChem 8.0.6 [10] is a molecular modelling program that allows to build and analyze different molecular structures and to determine the physico-chemical properties. The molecules of N-[p-(methylsalicylamidosulfonyl)-benzoyl]-L-glutamine (I) and $\mathrm{N}$-[p-(methyl-phenoxyacetate-

amidosulfonyl)-benzoyl]-L-glutamine

have been studied using molecular modelling program HyperChem 8.0.6 by one of the semi-empirical method PM3 [11-13].

The molecule was geometrically optimized using the Polak - Ribiere algorithm as convergence criterion and the maximum gradient used to optimize the studied chemical structures was $0.1 \mathrm{kcal} /$ (Á.mol). A calculation type "single point" and a number of physical and structural properties have been obtained, after the molecular geometry optimization.

The energy difference $\Delta \mathrm{E}$ is proportional to the electrophilicity index of compunds and offers information about the compound biological activity.

The ionization potential and electron affinity can be estimated from the values of HOMO and LUMO energies, by applying theorem Koopmans [14].

$$
\begin{aligned}
& \mathrm{I}=-\mathrm{E}_{\text {HOMO }} \\
& \mathrm{A}=-\mathrm{E}_{\text {LUMO }}
\end{aligned}
$$

Quantitative Structure - Activity

Relationships (QSAR) [15] modelling correlates the molecular structure or the properties derived from molecular structure with a particular kind of chemical or biochemical activity.

$\log \mathrm{P}[16]$ is related to the hydrophobic character of the molecule, which plays an important role in biochemical interactions. The lipophilicity [17] is a determining factor in the adsorption and distribution of the compounds in the human body.

\subsection{Factorial experiment for reaction optimization}

The $3^{2}$ factorial program (in which 3 is the level of the variation of the relevant variables and 2 is the number of significant variables) was used in order to establish the most convenient conditions for chemical reaction in which the studied compounds $[18,19]$ were obtained.

In our experiment the variables are: the reaction yield $(\mathrm{y})$, temperature $\left(\mathrm{x}_{1}\right)$ and the time interval of reaction $\left(\mathrm{x}_{2}\right)$. The adimensional relevant variables $\mathrm{x}_{\mathrm{i}},(\mathrm{i}=1,2)$ are computed [20-22] as function of:

$$
\overline{X_{i}}=\frac{X_{i \min }+X_{i \max }}{2}
$$

The correlation between the adimensional variable $\mathrm{x}_{\mathrm{i}}(\mathrm{i}=1,2)$ and the real variable $X_{i}(i=1,2)$ is given by :

$$
X_{i}=\overline{X_{i}}+x_{i} \Delta X_{i}
$$

Where $\overline{X_{i}}$ is the average value of the real variation domain and $\Delta X_{i}$ is the half of the real variation domain [19].

The estimations are made in adimensional variables which allow rapid calculations and then the real values are obtanied by using relation (4).

The polynomial model used for optimization reaction takes into consideration 
the both singular influence of the relevant variables and its sinergetic influence:

$$
y=a_{0}+a_{1} x_{1}+a_{2} x_{2}+a_{12} x_{1} x_{2}+a_{11} x_{1}^{2}+a_{22} x_{2}^{23}
$$

This statistic technique of the $3^{2}$ factorial program permits to avoid a large series of experiments for determining the model coefficients.

\section{Results and discussions}

3.1. Optimization of the obtaining reactions for compounds $I$ and II

For the beginning, $3^{2}=9$ experiments were organised and the results are given in Table 1 for the studied substances (I) and (II).

Table 1 Adimensional (real) variables $x_{i}\left(X_{i}\right), i=1,2$ and reaction yield $y$ for

\begin{tabular}{|c|c|c|c|c|c|c|}
\hline$x_{1}\left(X_{1}^{\circ} \mathrm{C}\right)$ & $x_{2}\left(X_{2}\right.$ min $)$ & $x_{1} x_{2}$ & $x_{1}{ }^{2}-2 / 3$ & $x_{2}{ }^{2}-2 / 3$ & $y_{I}$ & $y_{I I}$ \\
\hline$-1(116)$ & $-1(58)$ & 1 & $1 / 3$ & $1 / 3$ & 76 & 60 \\
$-1(116)$ & $0(60)$ & 0 & $1 / 3$ & $-2 / 3$ & 80 & 63 \\
$-1(116)$ & $1(62)$ & -1 & $1 / 3$ & $1 / 3$ & 77 & 60 \\
$0(118)$ & $-1(58)$ & 0 & $-2 / 3$ & $1 / 3$ & 79 & 60 \\
$0(118)$ & $0(60)$ & 0 & $-2 / 3$ & $-2 / 3$ & 83 & 65 \\
$0(118)$ & $1(62)$ & 0 & $-2 / 3$ & $1 / 3$ & 80 & 63 \\
$1(120)$ & $-1(58)$ & -1 & $1 / 3$ & $1 / 3$ & 77 & 61 \\
$1(120)$ & $0(60)$ & 0 & $1 / 3$ & $-2 / 3$ & 81 & 64 \\
$1(120)$ & $1(62)$ & 1 & $1 / 3$ & $1 / 3$ & 79 & 62 \\
\hline
\end{tabular}

The coefficients $a_{0}-a_{22}$ of the model (5) were computed by statistical means.
The results for the studied compounds are listed in Table 2.

Table 2 Polynomial coefficients of relation (5)

\begin{tabular}{|c|c|c|c|c|c|c|}
\hline Compound & $a_{0}$ & $a_{1}$ & $a_{2}$ & $a_{12}$ & $a_{11}$ & $a_{22}$ \\
\hline I & 82.888 & 0.667 & 0.667 & 0.25 & -2.333 & -3.333 \\
II & 64.666 & 0.667 & 0.667 & 0 & -1 & -3 \\
\hline
\end{tabular}

The t-student test must be made in variation domain were organized and the order to decide if these coefficients are the obtained data in these experiments are listed best. Three experiments in the center of the in Table 3.

Table 3 Yield values in the middle of the variation domain $\eta_{i c}(i=1,2,3)$, the average yield in center of variation range $\bar{\eta}_{c}$, square average deviation $S_{\eta}$, precision $P$

\begin{tabular}{|c|c|c|c|c|c|c|c|}
\hline Compound & $\eta_{1 c}$ & $\eta_{2 c}$ & $\eta_{3 c}$ & $\bar{\eta}_{c}$ & $\Delta \eta_{i c}$ & $S_{\eta}$ & $P$ \\
\hline I & 82 & 83 & 82 & 82.333 & 0.333 & 0.333 & 0.192 \\
II & 65 & 64 & 63 & 64 & 1 & 1 & 0.333 \\
\hline
\end{tabular}

The t-student coefficients can be three experiments. The values of the t-student computed using the same precision $\mathrm{P}$ for the coefficients are listed in Table 4.

Table 4 T-student coefficients of obtaining reaction for compounds I and II

\begin{tabular}{|c|c|c|c|c|c|c|}
\hline Compound & $t_{0}$ & $t_{1}$ & $t_{2}$ & $t_{12}$ & $t_{11}$ & $t_{22}$ \\
\hline I & 431.718 & 3.489 & 3.489 & 1.302 & 12.151 & 17.359 \\
II & 194.19 & 2.003 & 2.003 & 0 & 3.003 & 9.009 \\
\hline
\end{tabular}

The t-student coefficient smaller than corresponding variable on the reaction yield unity indicates a small influence of the and the term with this coefficient must be 
eliminated. The real values for the maximun yield of reactions are listed in Table 5.

Table 5 Real values for the maximum of the reaction yield

\begin{tabular}{|c|c|c|c|}
\hline Compound & $x_{1 e}\left(X_{1}{ }^{\circ} \mathrm{C}\right)$ & $x_{2 e}\left(X_{2} \min \right)$ & $y_{e}(\%)$ \\
\hline I & $0.15(117.15)$ & $0.10(60.20)$ & 82.38 \\
II & $0.35(118.7)$ & $0.13(60.25)$ & 64.82 \\
\hline
\end{tabular}

The relations in which the reaction

$0.25 \mathrm{x}_{1} \mathrm{x}_{2}-2.333 \mathrm{x}_{1}^{2}-3.333 \mathrm{x}_{2}^{2}$

yield is expressed by relevant variables and

by their products are the following:

$\mathrm{y}_{\mathrm{II}}=64.67+0.67 \mathrm{x}_{1}+0.67 \mathrm{x}_{2}+0.25 \mathrm{x}_{1} \mathrm{x}_{2}-\mathrm{x}_{1}^{2}$

$\mathrm{y}_{\mathrm{I}}=82.89+0.67 \mathrm{x}_{1}+0.67 \mathrm{x}_{2}+$

$-3 \mathrm{x}_{2}^{2}$

(7)

3.2. Calculation results using HyperChem calculated.

8.0.6

By using the molecular modelling software, the main physical-chemical characteristics of sulfonamides were

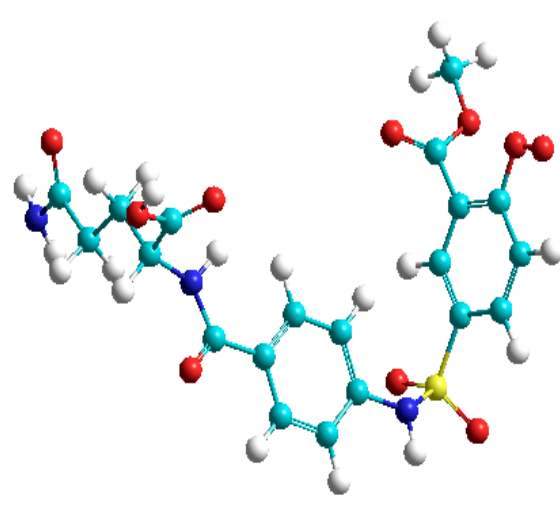

a) Compound I
The optimized geometry of compounds (I) and (II) are represented in figure $1(a$ and $b)$.

\section{characteristics of sulfonamides were}

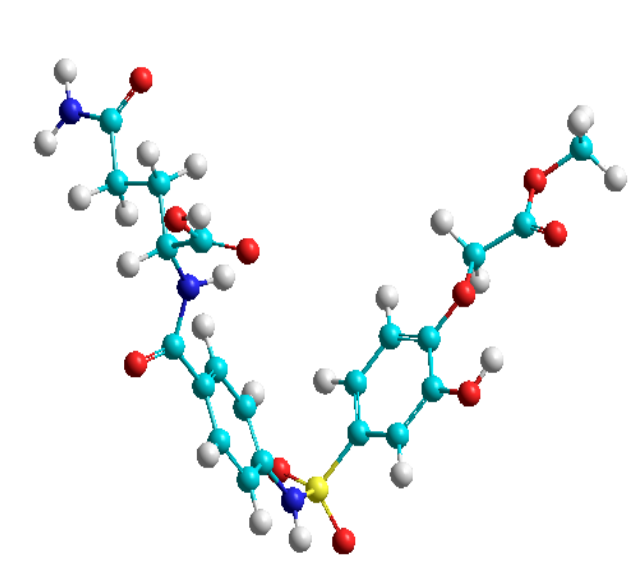

b) Compund II

Figure 1 The optimized structures of compounds (colors for atoms are as follows: carbon-green, nitrogen-blue, oxygen-red, hydrogen-white and sulfur-yellow)

The QSAR parameters calculated from HyperChem program for compounds I and II are listed in table 6 and the the electro- optical properties resulting from HyperChem program are listed in table 7.

Table 6 QSAR parameters calculated by HyperChem using semi-empirical method PM3

\begin{tabular}{|c|c|c|}
\hline Parameters QSAR & Compound I & Compound II \\
\hline Log P & -3.55 & -4.38 \\
Hydration energy $(\mathrm{kcal} / \mathrm{mol})$ & -25.69 & -28.54 \\
Refractivity $\left(\AA^{3}\right)$ & 120.73 & 127.25 \\
Polarizability $\left(\AA^{3}\right)$ & 42.22 & 44.69 \\
Mass (u.a.m) & 479.46 & 509.48 \\
Surface Area $\left(\AA^{2}\right)$ & 667.60 & 742.62 \\
Volume $\left(\AA^{3}\right)$ & 1242.18 & 1333.83 \\
\hline
\end{tabular}


Table 7 The electro-optical properties resulting from HyperChem program by method PM3 for compound I and II

\begin{tabular}{|c|c|c|}
\hline Properties & Compound I & Compound II \\
\hline Total energy $(\mathrm{kcal} / \mathrm{mol})$ & -138588.44 & -148793.3931 \\
Binding energy $(\mathrm{kcal} / \mathrm{mol})$ & -5768.4577 & -6132.8584 \\
Heat of formation $(\mathrm{kcal} / \mathrm{mol})$ & -315.0847 & -344.8324 \\
Dipole moment $(\mathrm{Debye})$ & 4.878 & 5.456 \\
$\mathrm{E}_{\mathrm{LUMO}}(\mathrm{eV})$ & -1.21276 & -1.1913 \\
$\mathrm{E}_{\mathrm{HOMO}}(\mathrm{eV})$ & -9.29476 & -9.2786 \\
$\Delta \mathrm{E}=\mid \mathrm{E}_{\mathrm{HOMO}}-\mathrm{E}_{\mathrm{LUMO}}(\mathrm{eV})$ & 8.082 & 8.0873 \\
\hline
\end{tabular}

A negative value of $\log \mathrm{P}$ indicates that the compound is hydrophilic while the positive values of $\log \mathrm{P}$ shows that the studied compound is lipophilic. The studied compounds are hydrophilic.

The stability of the studied molecular structures is given by their high values of negative total energy.

\section{Toxicity evaluation}

The Spearman-Karber arithmetic method [23] was used in determining the lethal dose $50 \% \quad \mathrm{LD}_{50}$. The final formula in this method is (8):

$$
D L_{50}=D L_{100} \frac{\sum(a \times b)}{n}
$$

where: a - the difference between two successive doses of the substance administered; $b$ - the average number of dead animals of two consecutive batches; $\mathrm{n}$ - the number of mortalities in a batch; $\mathrm{DL}_{100}-$ the lethal dose $100 \%$.

The results of the toxicity study (Table 8), based on Spearman-Kärber method, confirm that the using $\mathrm{N}-(\mathrm{p}-$ aminobenzoyl)-L-glutamine as transport agent for sulphonamide residues significantly influence the toxicity diminishing and requires further research to establish their bacteriostatic activity.

Lots of 6 white male mices were used in order to determine the acute toxicity of the two new sulphonamides.

The substances tested (I, II) were administered intraperitoneally as a suspension in Tween 80 and the mortality was recorded 24 hours, 48 hours and 7 days.

The values of $\mathrm{DL}_{50}$ for the synthesized compounds were compared with the acute toxicity of sulfametoxazole finding the values below than these.

Table 6 The results of the toxicity study for compound I and II

\begin{tabular}{|c|c|c|c|c|}
\hline \multirow{2}{*}{ Compounds } & \multicolumn{4}{|c|}{ DL $_{50}(\mathrm{mg} / \mathrm{kg}$ body) } \\
\cline { 2 - 5 } & 24 hours & 48 hours & 7 days & Average \\
\hline I & 8500 & 8500 & 8350 & 8460 \\
II & 8720 & 8730 & 8640 & 8693 \\
Sulfamethoxazole & 2600 & 2600 & 1750 & 2316 \\
\hline
\end{tabular}

The new synthesized compounds are non-toxic and the $\mathrm{DL}_{50}$ values recommend them for the laboratory screening.

\section{Conclusions}

The $3^{2}$ experiments organised in order to optimize the reaction yield for obtaining compounds I and II avoid the big number of experiments made for establish the favorable conditions of the chemical reaction.
The highest values of the reaction yield for obtaining the compounds I and II are of about $85 \%$ and $63 \%$, respectively.

Having in view the values of the relevant variables corresponding to the maximum of the reaction yield, the reaction can be made at real values of the relevant variables with the precursors quantities conducting to a given quantity of the chemical product. 
The electro-optical properties and QSAR parameters of the synthesized compounds obtained by using HyperChem 8.0.6 program recommend compounds I and II as biologically active substances.

The toxicity evaluation of synthesized sulphonamides was established by $\mathrm{DL}_{50}$, which recommend them for antibacterial and antifungal activity testing.

Acknowledgments: This research was financially supported by the Internal research grant of University of Medicine and Pharmacy "Grigore T. Popa" Iasi Nr. 30878/30.12.2014.

\section{References}

[1] M. E. Wolff, Ed. Burger's, Medicinal Chemistry and Drug Discovery, 6th edition. Wiley, New York, 2003.

[2] (a) C. Esteve, B. Bidal, Tetrahedron Letters, Vol. 43, pp. 1019, 2002.

(b) Z. Xiao, J. W. J. Timberlake, Heterocyclic Chemistry, Vol. 37, pp. 773, 2000.

(c) A. Martinez, C. Gil, C. Prez, A. Castro,C. Prieto, J. Otero, G. Andrei, R. Snoek, J. Balzarini, E. D. J. Clercp, Medicinal Chemistry, Vol. 43,pp. 3267, 2000.

(d) R. Kuang, R. Venkataraman, S. Ruan, W. C. Groutas, Bioorganic and Medicinal Chemistry Letters, Vol. 8, pp. 539, 1998.

(e) C. H. Lee, H. J. Kohn, Journal of Pharmaceutical Sciences,Vol. 70, pp.716, 1990.

(f) C.H. Lee, J. D. Korp, H.J. Kohn, Journal of Organic Chemistry, Vol. 54, pp. $3077,1989$.

[3] K. Gaurov, R. K. Goel, M. Shukla, M. Pandey, Indian Journal of Medical Pediatric Oncology, Vol. 33, pp. 13, 2012.

[4] W. Yuliang, J. Yaozhong, Synthetic Communications, Vol. 22, pp. 2287, 1992.

[5] J. Micklefield, K. J. Fetles, Tetrahedron Letters, Vol. 38, pp. 5387, 1997.

[6] M. Travnicek, M. Potacek, Molecules, Vol. 4, pp. 238, 1999.

[7] S. Joshi, N. Khosla, D. Khare, P. Tiwari, Acta Pharmaceutica,Vol. 52, pp. 1971, 2002.

[8] M. Moise, V. Șunel, L. Profire, M. Popa, C. Lionte, Farmacia, Vol. 16, pp. 283, 2008.

[9] D. Grebinișan, M. Holban, V. Șunel, M. Popa, J. Desbrieres, C. Lionte, Cellulose Chemistry and Technology, Vol. 45, pp. 571, 2011.

[10] www.hyper.com (HyperChem, Molecular visualisation and simulation program package, Hypercube, Gainsville, F1, 32601)

[11] J. J. P. Stewart, Computational Chemistry, Vol. 10, No. 2, pp. 209, 1989.

[12] T. Schilk, Molecular modeling and simulation. An Interdisciplinary Guide, Springer, Velag, New York, 2002.

[13] R. D. Lide, Handbook of Chemistry and Physics, Boca Raton, Florida, CRC Press, 2005.

[14] T. Koopmans, Physica (Elsevier), Vol. 1, No.1-6, pp. 104-113, 1934.

[15] S. A. Gallegos, Molecular Quantum Similarities in QSAR: Applications in ComputerAided Molecular Design. PhD Thesis, Universitat de Girona, 2004.

[16] F. Jaroš, T. Straka, Z. Dobešova, M. Pinterova, K. Chalupsky, J. Kuneš, G. Entlicher, J. Zicha, European Journal of Pharmacology,pp. 575, 2007.

[17] R. Parthasarathi, V. Subramanian, D. R. Roy, P. K. Chattaraj, Bioorganic \& Medicinal Chemistry. In Advanced Methods and Applications in Chemoinformatics: Research Progress and New Applications, Eduardo Alberto Castro, A.K. Haghi, Eds., 2012.

[18] I. Fisher, Design for Environment, Creating Eco-Efficient Products and Processes, Ed. Mc. Graw Hill, New York, 1996.

[19] A. Azzouz, M. Leontie, D. O. Dorohoi, C. Gheorghies, Elemente de strategie în design industrial, Ed. Plumb, Bacau, 1998. 
[20] D. Grebinisan, N. Burlea, C. Cheptea, C. Lionte, D. O. Dorohoi, V. Sunel, M. Popa, I. Hurjui, Digest Journal of Nanomaterials and Biostructures, Vol. 8, no. 2, pp. 777-785, 2013.

[21] I. Hurjui, C. Cheptea, C. F. Dascalu, L. Hurjui, C. Peptea, V. Sunel, D. O. Dorohoi, Digest Journal of Nanomaterials and Biostructures, Vol.7, no. 4, pp. 1747-1756,2012.

[22] C. Cheptea, M. Dulcescu, D. O. Dorohoi, V. Sunel, J. Debuer-Deloriere, Digest Journal of Nanomaterials and Biostructures, Vol. 7, No.1, pp. 287-297, 2012.

[23] S. Kärber, Environmental Science and Technology, Vol. 11, pp. 714, 1977. 